ASCLEPIO. Revista de Historia de la Medicina y de la Ciencia

67 (1), enero-junio 2015, p080

ISSN-L:0210-4466

http://dx.doi.org/10.3989/asclepio.2015.06

DOSSIER: CIENCIA Y SABERES AGRÍCOLAS EN CONSTRUCCIÓN EN LA HISTORIA DE AMÉRICA LATINA Y EL CARIBE:

AGENTES, REDES Y CÍRCUITOS (SIGLOS XVIII-XX) / AGRICULTURAL SCIENCE AND KNOWLEDGE IN CONSTRUCTION IN

THE HISTORY OF LATIN AMERICA AND THE CARIBBEAN: NETWORKS, ACTORS AND CIRCUITS (XVIII-XX CENTURIES)

\title{
SABERES HÍBRIDOS: LAS SUGAR COMPANYS Y LA MODERNA PLANTACIÓN AZUCARERA EN CUBA
}

\author{
Leida Fernández Prieto \\ Instituto de Historia, CCHS-CSIC \\ leida.fernandez@cchs.csic.es
}

Recibido: 10 noviembre 2014; Aceptado: 1 febrero 2015.

Cómo citar este artículo/Citation: Fernández Prieto, Leida (2015), "Saberes Híbridos: Las Sugar Companys y la moderna plantación azucarera en Cuba", Asclepio 67 (1): p080. doi: http://dx.doi.org/10.3989/asclepio.2015.06

RESUMEN: Desde los estudios sobre la producción y difusión del conocimiento, este texto explora el encuentro e intercambio entre prácticas y saberes locales y globales dentro de la plantación azucarera entre los siglos XIX y XX, un proceso definido como "saberes híbridos". Este artículo también se hace eco de los estudios que ven en la región como modelo de referencia interterritorial. En el texto se destacan algunos elementos del occidente azucarero cubano transferidos a las nuevas plantaciones del este a través de la negociación entre el conocimiento local y las prácticas y saberes estadounidenses, no exenta de tensiones personales, imperiales, científicas o empresariales.

PALABRAS CLAVE: Plantación; Conocimientos; Sugar companys; Manuel Rionda; William Van Horne.

\section{HYBRID KNOWLEDGE: THE SUGAR COMPANYS AND THE MODERN SUGARCANE PLANTATION IN CUBA}

ABSTRACT: From the studies on the production and dissemination of knowledge, this paper explores the encounter and exchange between local and global practices and knowledge within the sugar plantation between the nineteenth and twentieth centuries, a process defined as "hybrid knowledge". This article echoes the studies are in the region as a model of interregional also referred. Highlights some elements of Western Cuba sugar transferred to new plantations east through negotiation between local knowledge and practices and American knowledge, not without personal, imperial, scientific or businesstensions.

KEY WORDS: Sugarcane plantation, Knowledge; Sugar companys; Manuel Rionda; William Van Horne.

Copyright: () 2015 CSIC. Este es un artículo de acceso abierto distribuido bajo los términos de la licencia Creative Commons Attribution-Non Commercial (by-nc) Spain 3.0. 


\section{INTRODUCCIÓN}

La historia de la industria azucarera tropical en general y cubana en particular, ha estado indisolublemente vinculada a las compañías privadas azucareras trasnacionales (sugar companys o sugar trust) a lo largo del siglo XX. En una mirada de larga duración, las compañías azucareras fueron también testigos de dos procesos trascendentales para la historia política de Cuba: el tránsito de colonia a república mediada por la primera ocupación norteamericana en el país (1898-1902) y de república a revolución (1902-1959). Las ruinas que hoy podemos ver en el campo cubano de muchos de los centrales -fábricas azucareras- implantados por las sugar companys y antiguos buques insignias de modernidad, reflejan el actual declive de la principal industria cubana.

La actuación de las compañías azucareras cuenta con una amplia literatura que parte de diversos enfoques historiográficos y temáticos para América latina y el Caribe. Varios estudios subrayan la participación de las compañías azucareras trasnacionales como instrumentos del imperio estadounidense en la región (Zanetti y García, 1976; Pino Santos, 1960; Pérez, 1983). Otros trabajos consideran la influencia clave de Estados Unidos y las empresas azucareras para el desarrollo y la modernización del Caribe hispano (Ayala, 1999; Nadel, 2007). Para los historiadores ambientales y de la ciencia, las compañías azucareras son un ejemplo paradigmático de imperialismo ecológico a partir de las consecuencias negativas de su uso intensivo de los recursos naturales latinoamericanos y caribeños (expansión del latifundio y el monocultivo, mayor degradación ambiental, etc.) (Tucker, 2000; McCook, 2002a y 2002b; Soluri, 2005; Funes, 2004).

Cuba es un terreno poco explorado por parte de los estudios centrados en el lugar y la práctica para documentar la construcción de una ciencia más abierta que trascienda las fronteras entre centros y periferias, local/global (Chambers y Gillespie, 2001, pp. 221-240). En particular, destacan los trabajos de McCook (2002a y 2009) y Raby (2012) que analizan el papel de las estaciones experimentales agronómicas y biológicas en el Caribe para la formación de los estadounidenses en la ciencia tropical.

No existen estudios, sin embargo, sobre las compañías azucareras trasnacionales como foco de producción y diseminación de saberes y prácticas científicas a diversos niveles (global, regional, local). Sin embargo, estas empresas ilustran la forma en que un gru- po de agentes socioeconómicos ponen en marcha diversas agendas de investigación, experimentación e intercambio agrícola; un estudio pendiente en la historia de la construcción de los saberes y prácticas de la ciencia azucarera tropical. En el caso cubano, las compañías azucareras privadas suplieron la ausencia de una estación experimental gubernamental dedicada exclusivamente a la industria azucarera. Se convirtieron, pues, en las agencias mediadoras para desarrollar e intercambiar programas globales de modernización agroindustrial fundados en el manejo local de los recursos naturales. Por ejemplo, ensayaron y difundieron variedades e híbridos cañeros y de fertilización adaptados a la productividad y/o erosión de los suelos cubanos. A la vez, en su seno se formaron expertos que contribuyeron al conocimiento de la ciencia agrícola global.

Desde los estudios sobre la producción y difusión del conocimiento, este texto explora el encuentro e intercambio entre prácticas y saberes locales y globales dentro de la plantación azucarera ${ }^{1}$ entre los siglos XIX y XX, un proceso definido como "saberes híbridos"2. La metáfora híbrido sugiere la multiplicidad de los agentes socioeconómicos que intervinieron en el proceso de renovación de la plantación, pero también alude a las tensiones que se producen en zonas de frontera y de intercambio cultural. La irrupción acelerada de las sugar companys y del capital norteamericano en la mitad este de Cuba visibilizó una zona de frontera entre el antiguo núcleo de la industria azucarera colonial del occidente y los nuevos espacios abiertos a la producción azucarera en el este. Es decir, una línea entre un know-how agroindustrial validado en las condiciones ambientales y económicas locales de producción y la experimentación práctica desde, al menos, finales del siglo XVIII y otras fuentes de conocimiento y prácticas asociados a la historia agroindustrial y empresarial de Estados Unidos. De igual modo, la plantación del siglo XX pone de manifiesto la existencia de una difusa frontera entre el conocimiento amateur y el experto, entre el laboratorio y el campo.

Este artículo también se hace eco de los estudios que ven en la región como modelo de referencia interterritorial (Vetter, 2005 y 2011). En el texto se destacan algunos elementos del occidente azucarero cubano transferidos a las nuevas plantaciones del este a través de la negociación entre el conocimiento local y las prácticas y saberes estadounidenses, no exenta de tensiones personales, imperiales, científicas o empresariales. Para ello, se siguen las actuacio- 
nes de dos figuras representativas del mundo azucarero entre los siglos XIX y XX. Por un lado, el hispanoestadounidense Manuel Rionda y Polledo, un viejo conocedor y activo testigo de la modernización de la industria azucarera colonial; por otro, el estadounidense William Cornellius Van Horne, presidente de la Cuba Company, símbolo de las nuevas prácticas introducidas por Estados Unidos. Rionda y Van Horne ejemplifican, en este sentido, dos tipos de know how que confluyeron en la plantación azucarera de inicios del siglo XX en los que se entremezclaban las viejas redes clientelares coloniales y el nuevo contexto poscolonial, más favorable a la actuación de las corporaciones transnacionales.

En el primer apartado se describe el modelo productor del occidente adaptado al deterioro de las condiciones ambientales y económicas y su posterior trasvase como referente hacia la mitad este de Cuba. En el segundo apartado se subrayan los conocimientos y prácticas asociados, sobre todo, a la moderna agricultura y al modelo agroindustrial estadounidense.

\section{OCCIDENTE CONQUISTA EL ESTE DE CUBA}

Los estudios regionales distinguen tradicionalmente entre la Cuba $A$, coincidente con el occidente azucarero y más desarrollado y la Cuba $B$, situada en la mitad este del territorio (figura 1), más diversificada, pero más atrasada (Pérez de la Riva, 1968, pp. 22-39, 1975 y 2004; Venegas, 2001). Desde el enfoque de la historia de la ciencia, este apartado sostiene que la región del occidente aportó el know how azucarero validado en las condiciones locales ambientales y económicas de producción y en la experimentación práctica de múltiples agentes socioeconómicos (hacendados, reformadores agrícolas, ingenieros, agentes de casas comerciales y de maquinarias, etc.). Así, el occidente productor cubano actuó como "isla del saber"3 para difundir conocimientos y prácticas agrícolas hacia la mitad este de Cuba. Rionda y Van Horne ilustran este proceso en las nuevas plantaciones azucareras a través de la propagación de variedades e híbridos cañeros, el uso de abonos, así como la reapertura de las antiguas conexiones y redes coloniales dentro de los circuitos azucareros globales y locales.

Figura 1. Mapa de Cuba. La provincia de Santa Clara fue el límite entre el occidente azucarero y el este más diversificado hasta inicios del siglo XX

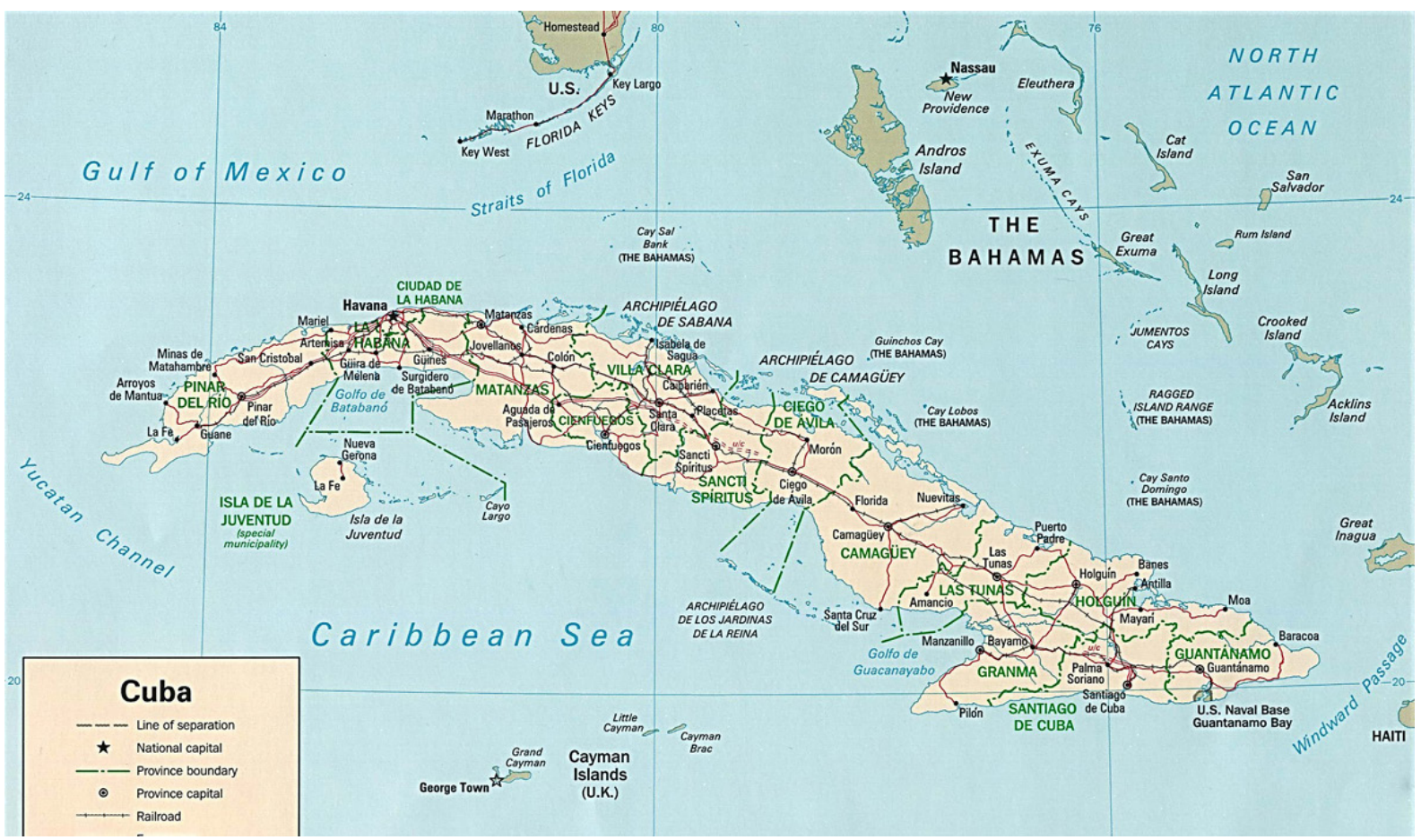


La amplia documentación generada por las compañías de los dos empresarios ha sido objeto de interés para diversos estudiosos. Robert N. Lauriault describe la construcción del central Francisco Sugar Company, propiedad mayoritariamente de Rionda, desde una perspectiva crítica con la participación norteamericana y la conversión del colono independiente en un proletariado rural (Lauriault, 1994). Este autor resalta aspectos sobre agricultura, medioambiente y sociedad local, si bien alejados del enfoque de la historia de la ciencia. Otros textos señalan las complejas redes trasnacionales y locales que tanto William Van Horne como Manuel Rionda forjaron a lo largo de trayectorias empresariales. El estudio de Juan Carlos Santamarina es, probablemente, el más completo sobre la participación de Van Horne y la Cuba Company en la modernización de la industria azucarera de la mayor de las Antillas (Santamarina, 1995 y 2001, pp. 7590). Muriel McAvoy es la biógrafa por excelencia de Manuel Rionda y sus negocios azucareros hasta el triunfo de la revolución cubana (McAvoy, 2003). Gillian McGilliwray explora la documentación acerca de las relaciones entre campesinos, colonos y hacendados en la formación del estado republicano cubano en el contexto de procesos políticos similares en América latina y el Caribe, en particular el fenómeno del caudillismo (McGilliwray, 2009).

Sin embargo, ningún trabajo observa la actuación de los dos empresarios como agentes socioeconómicos para la difusión de las prácticas y saberes que caracterizaron la agricultura azucarera en Cuba. Los estudios subrayan que las nuevas plantaciones repitieron los patrones culturales del occidente, consistentes en la alta adaptabilidad biológica y económica de la caña de azúcar al clima tropical y el aprovechamiento de la renta forestal (ocupar zonas boscosas como garantía de los altos rendimientos) (Moreno Fraginals, 1978; Santamaría, 2001; Funes, 2004). Las evidencias demuestran una estrategia empresarial que combinó el tradicional sistema de cultivo antes descrito y otro modelo de agricultura científica puesto en marcha en el occidente para responder a las condiciones de declive productivo, al ser este espacio el soporte de la preeminencia en el mercado mundial del azúcar de caña durante el boom agroexportador de la segunda conquista ambiental y económica latinoamericana y caribeña entre 1840 y 1930 (Topik y Wells, 1997).
En 1870, el asturiano Manuel Rionda y Polledo siguió la ruta trazada por las redes familiares en el camino hacia las Américas (McAvoy, 2003, p. 8). Francisco, el mayor de los hermanos, se había convertido en próspero comerciante y propietario de ingenio en Matanzas, la principal zona azucarera a mediados del siglo XIX y epicentro de la "revolución industrial cubana", caracterizada por la adopción en las fábricas azucareras de tecnologías y personal procedentes de los centros industriales de Inglaterra y Estados Unidos (Tomich y Funes, 2001, pp. 75-120; Curry-Machado, 2011).

Menos atendida por los estudiosos fue la revolución agrícola varietal que complementó la transformación industrial con la introducción de la variedad de caña de azúcar Cristalina, originaria de Java, en sustitución de la variedad Otahiti. Las dos formaban parte de los usuales intercambios globales de variedades azucareras entre los productores tropicales pero, para Cuba, fue una clara señal del nuevo momento que atravesaba la industria azucarera del occidente. Alrededor de 1790, la introducción y propagación de la variedad de caña Otahiti garantizó la expansión de la industria azucarera por todo el occidente para ocupar el lugar dejado por la colonia francesa de Saint-Domingue en el mercado azucarero mundial de finales del siglo XVIII. Es decir, su difusión se debió a la estrategia de la elite local conocedora del valor productivo demostrado por esta variedad en las tierras caribeñas, más que a factores ambientales (McCook, 2002 a, Fernández Prieto, 2005). Los debates alrededor de la degeneración de la caña Otahiti y la sustitución por la Cristalina incluían, en cambio, variables tanto económicas como ambientales: la decadencia productiva y la erosión de los suelos cubanos. El cultivo de la caña de azúcar Cristalina respondía mejor a los terrenos cansados del occidente cubano, era más resistente a las plagas y enfermedades agrícolas y de alta productividad. A partir de entonces dominó los campos azucareros.

La primera guerra independentista de los Diez Años (1868-1878) interrumpió otro momento fundacional para la adaptabilidad de la agricultura azucarera a la mayor degradación productiva de las condiciones medioambientales. La aplicación de la química para aumentar los rendimientos agrarios fue, quizá, la principal certeza de la entrada de la agricultura científica en Cuba asociada a factores ambientales. El naturalista gallego Ramón de la Sagra (1863) y el agrónomo habanero Álvaro Reynoso 
(1862) veían en la aplicación de los abonos el símbolo de los nuevos tiempos abiertos al triunfo de la ciencia sobre el empirismo y la rutina; su introducción indicaba también los límites productivos en aquellos terrenos sobreexplotados por el azúcar. Los dos constataban la conversión de los hacendados en experimentadores prácticos de diversos tipos de abonos para mejorar la productividad de sus cansadas plantaciones. Así, sus introductores y difusores (hacendados, agentes de las casas de abonos, etc.) fueron constructores de un know-how validado por Reynoso en el manual científico azucarero escrito en 1862 , un manual que fue otro ejemplo de los intercambios globales entre los productores tropicales al seguirse sus doctrinas en Java y Brasil.

Un año después, en 1863, el hacendado Miguel Aldama fue noticia al realizar por vez primera en Cuba ensayos con el arado de vapor sistema Fowler en su ingenio "Concepción", cuyos resultados no fueron entonces satisfactorios. La compañía inglesa, con sede en Leeds, fue una de las principales constructoras de maquinaria tropical, cuya presencia en la isla databa de una década anterior. Las críticas de los productores por no adaptar su tecnología a las condiciones locales pusieron en valor al trópico como un espacio clave para la fabricación in situ de las tecnologías de la agricultura tropical, sobre todo porque las casas de maquinaria de los centros industriales correspondían a la agricultura templada (Fernández Prieto, 2013, pp. 789-797).

La llegada de Rionda a Cuba coincidió con la revolución azucarera en el occidente y con la guerra independentista. Gracias a los vínculos tejidos por su hermano Francisco con Georges S. Hunt, dueño de Eagle Sugar Refinery radicada en Portland, Maine, se trasladó a Estados Unidos para estudiar en la Abbot School de Farmington. Con posterioridad fue agente de la filial norteamericana de la casa inglesa Czarnikow, MacDougall \& Company en la década de 1880. Muy pronto su habilidad empresarial destacó entre los círculos azucareros de Wall Street, donde sería conocido como "el rey del azúcar".

El fin de la guerra independentista evidenció la crisis económica de la industria azucarera. Para la historiografía sobre Cuba las soluciones fueron la transformación del antiguo ingenio en central, que separó la parte agrícola de la esfera industrial, la introducción de procesos de producción continuos, la descentralización de la oferta de caña en manos de los colonos tras la abolición de la esclavitud (1886) y el empleo del ferrocarril para extender las plantaciones hacia zonas vírgenes (Dye, 1998; Iglesias, 1999; Santamaría, 2001).

Todo ello es cierto, pero la crisis económica y ecológica selló un tercer momento clave para la consolidación de la agricultura científica en el modelo productor de la región occidental de Cuba (Fernández Prieto, 2005 y 2008). La disminución sostenida de los rendimientos agrícolas, el escaso crecimiento y aspecto enfermizo de la planta, la necesidad de realizar resiembras a los cuatro o cinco cortes (en lugar de los veinte que duraba un cañaveral en tierras vírgenes), fueron algunas cuestiones que los hacendados y colonos del occidente cubano afrontaron para competir con los restantes países azucareros de finales del siglo XIX. Surgió así un grupo importante de reformadores agrícolas y de hacendados que crearía, entre otras instituciones, la Escuela de Agricultura del Círculo de Hacendados.

Asimismo, la revista La Nueva Era retomó la necesidad de emplear los arados de vapor para sustituir la fuerza de trabajo. La publicación reconoció las imperfecciones de los primeros arados, si bien fueron modificados sobre el terreno por los propios fabricantes ingleses Fowler y Compañía, eliminando los inconvenientes. En 1891, Francisco y Manuel Rionda, junto a los inversores ingleses y norteamericanos, apostaron por el central Tuinicú (figura 2), pero la irrupción de la segunda guerra independentista de 1895 destruyó la plantación y aplazó las expectativas de sus dueños (Collazo, 2002, pp. 535-558).

En el verano de 1899, un año después de la primera ocupación norteamericana en Cuba, Manuel Rionda y Polledo reactivó su andadura en el negocio azucarero con capital británico y estadounidense, erigiendo en las tierras compradas por su hermano, en el sur de Camagüey, el central Francisco Sugar Company (figura 3), en honor a su hermano ya fallecido (Archives of Bragha Brother Collections y Archivo de las Tunas, Cartas entre Francisco y Manuel Rionda). Para ello, emplazó al administrador de ingenios Gabriel Menocal que construyera el central con todos los adelantos técnicos y científicos y que, sobre todo, fuese rentable: «Vamos a ver si entre Ud. y yo levantamos un Ingenio a la moderna y lo mejor y lo más económicamente posible. Todo el mundo nos va a estar mirando y es necesario que demos lecciones» (Archives of Bragha Brother Collections, Manuel Rionda Polledo, incoming correspondence 18961917, Serie 1, Box 14, Folder 15). 
Figura 2. Central Tuinicú. Archivo Provincial de Las Tunas

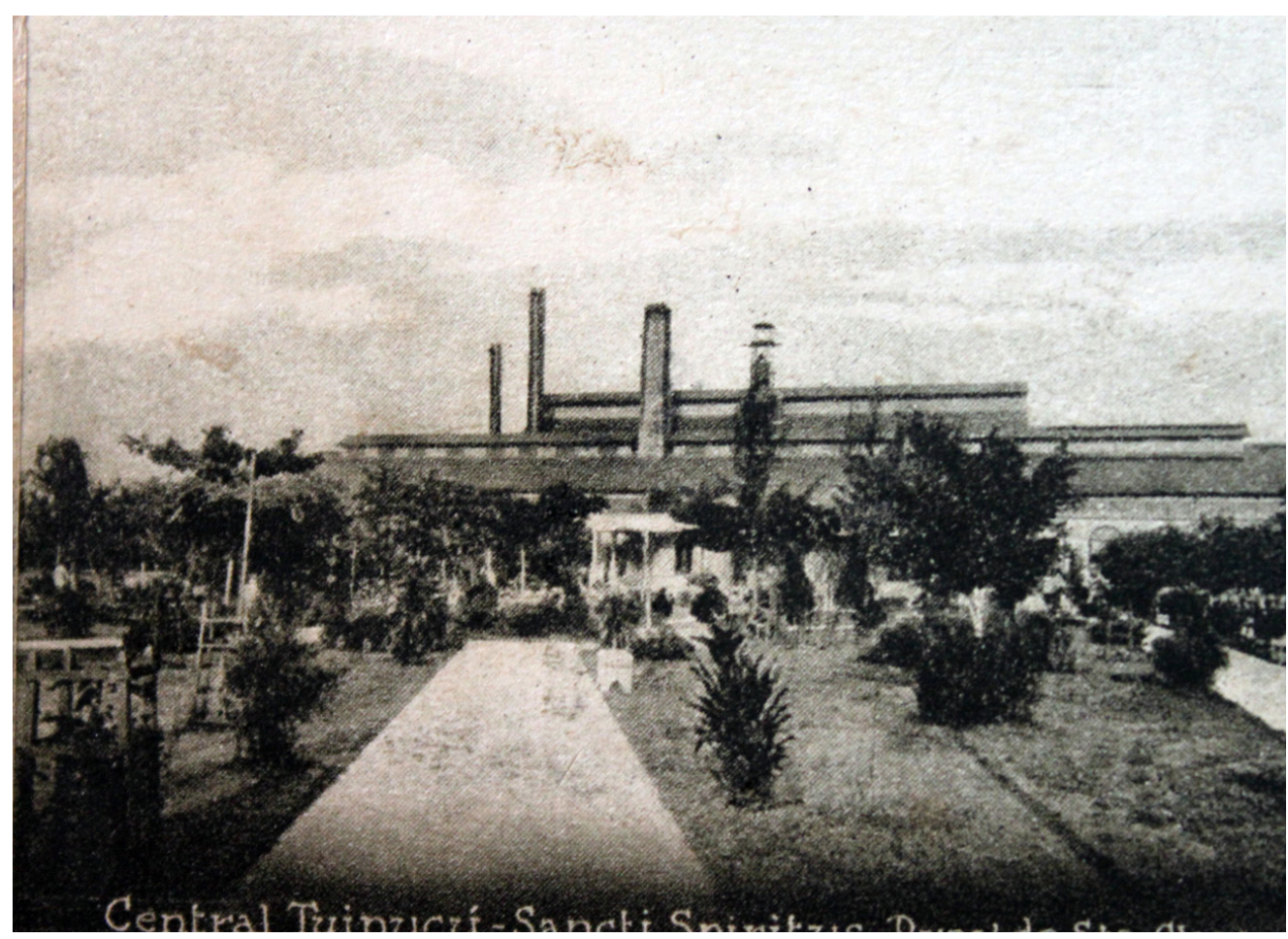

Figura 3. Central Francisco. Archivo Provincial de Las Tunas

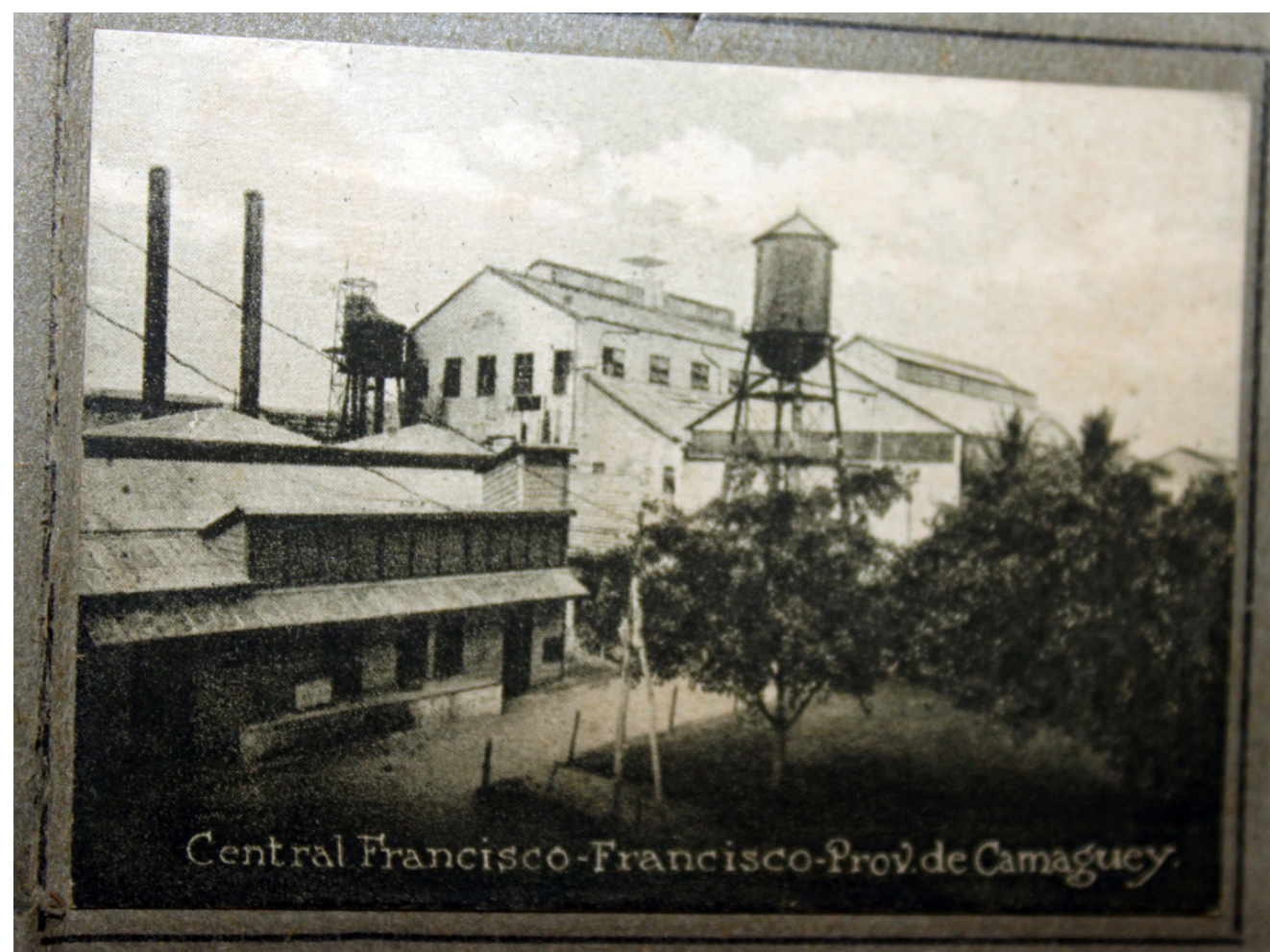


La primacía de Cuba en el mercado azucarero mundial a lo largo del siglo XIX, aportaba el pedigrí para impartir lecciones al mundo, un mundo azucarero que se entendía en clave global, aunque también, muy probablemente, Rionda se refería a Cuba y Estados Unidos como actores socioeconómicos principales del tejido empresarial y político. En este contexto entraba en escena William Cornelius Van Horne (figura 4), presidente de la Canadian Pacific Railroad entre 1889 y 1899. Van Horne se interesaba en la construcción del ferrocarril en la Guayana británica. Su visita a Cuba, en 1900, lo convirtió en artífice de la conquista azucarera del occidente hacia el este cubano. Van Horne y otros accionistas constituirá en New Jersey la Cuba Company con vistas a instalar el ferrocarril que conectara la Habana con Santiago de Cuba, lo cual posibilitaba no sólo ampliar la frontera del azúcar, sino que también abrir nuevos negocios agrícolas e industriales durante la expansión imperial estadounidense.

Figura 4. William C. Van Horne (1843-1915).

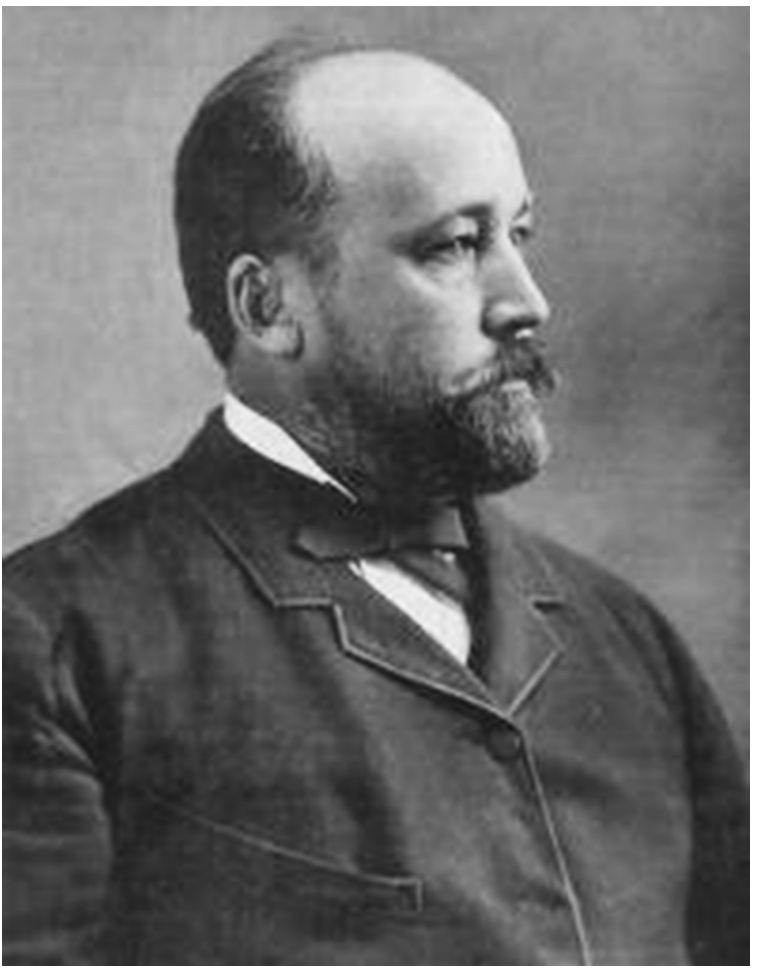

La compañía tuvo una amplia representación en los negocios de la isla y desarrolló varias estrategias para facilitar el acceso de nuevos inversores norteamericanos. En 1904, la compañía invirtió 4 millones de dólares para poner en marcha plantaciones de azúcar e ingenios. Así, en 1906 se erigió el central Jatibonico y en 1909 el Jobabo (figura 5), situados los dos entre Camagüey y Santiago de Cuba, en el extremo este de la isla de Cuba. Según Santamarina los dos centrales producían en torno a 145.000 toneladas de azúcar por año, cuya producción en gran escala fue facilitada por el ferrocarril y por las grandes extensiones de tierra que poseían. Por ejemplo, el Jobabo, considerado el coloso azucarero del sur de las Tunas, contaba con 3.013 caballerías aunque no todas cultivadas. Para Santamarina los dos ingenios fueron establecidos por Van Horne como un experimento que demostrara las ganancias que ofrecía el oriente cubano para el negocio azucarero (Santamarina, 2001, pp. 75-90).

Por su parte, Manuel Rionda, a la muerte de Czarnikow y tras la retirada de McDougal, refundó la firma inglesa bajo el nombre Czarnikow Rionda Company, y con capital financiero estadunidense. En 1907, Rionda fundó la Cuban Trading Company y en 1912, la Manati Sugar Company (figura 6), conformada por la unión de los centrales Tuinicú, Francisco, Elia, Céspedes y Manatí. En 1915, Manuel Rionda dirigió la Cuba Cane Sugar, creada para hacer frente al aumento de la demanda del azúcar provocada por la I guerra mundial (Santamaría 2001, p. 47). Fue considerada en su época la mayor empresa azucarera del mundo.

Los caminos de Rionda y Van Horne convergieron en algunos aspectos para modernizar sus centrales y plantaciones durante el inicio del siglo XX en qué ellas se observa el occidente como modelo productor y los puntos de conexión con antiguas casas y agentes empresariales establecidos en la Cuba colonial, así, por ejemplo, en el sector de la fabricación, Rionda recuperó la casa comercial Pesant y Krajewski, gracias a la amistad previa con J. M Clark, el agente de ellos en Matanzas.

Rionda ordenaba que le enviasen a sus oficinas de Nueva York muestras de caña y sacaran fotografías de todas las operaciones agrícolas para convencer a los inversores norteamericanos. Asimismo, se valió de planos y mapas con todos los cañaverales numerados para seguir todas las operaciones (figuras $7 a$ y $7 b$ ). 
Figura 5. Central Jobabo. Archivo Provincial de Las Tunas

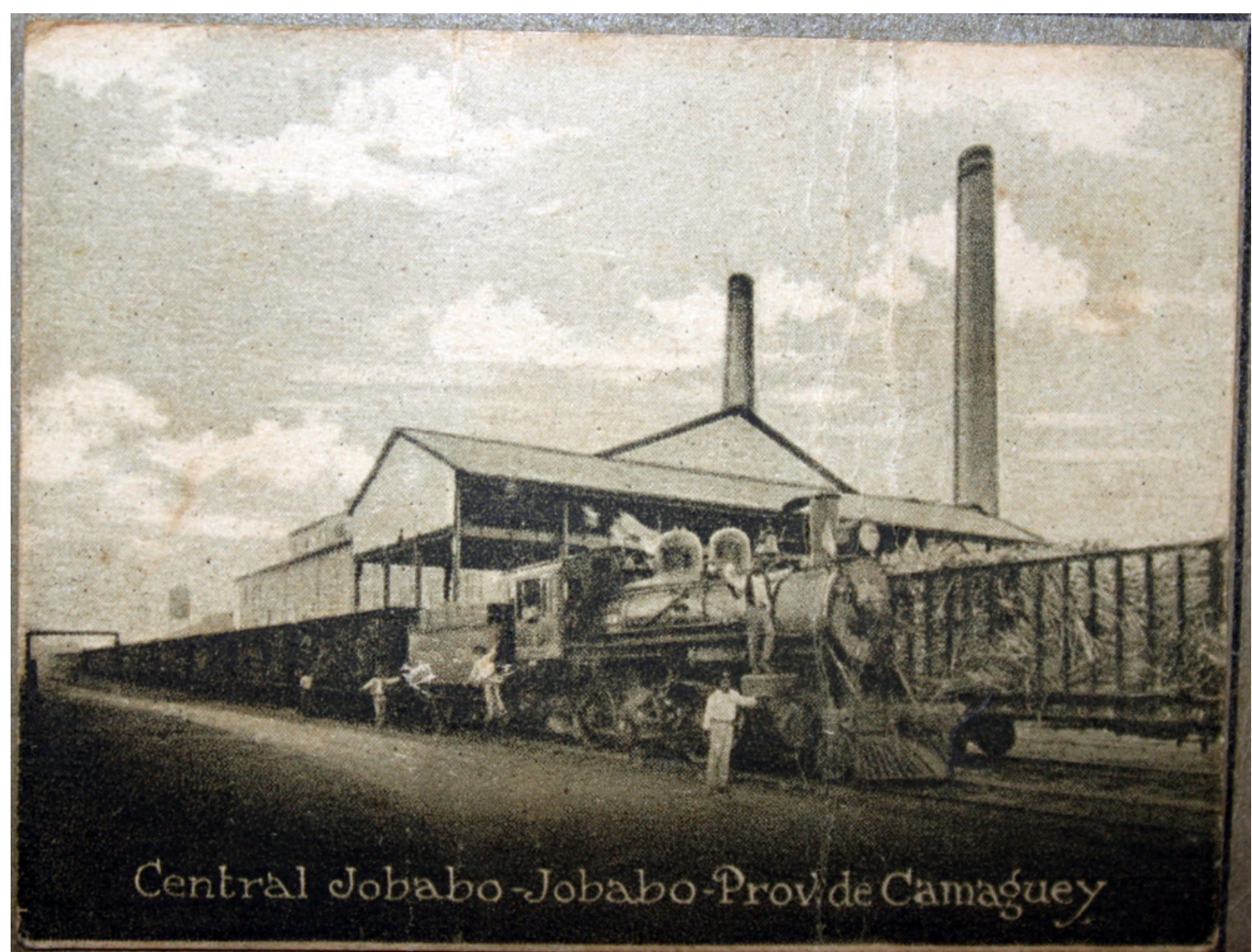

Figura 6. Central Manatí. Archivo Provincial de Las Tunas

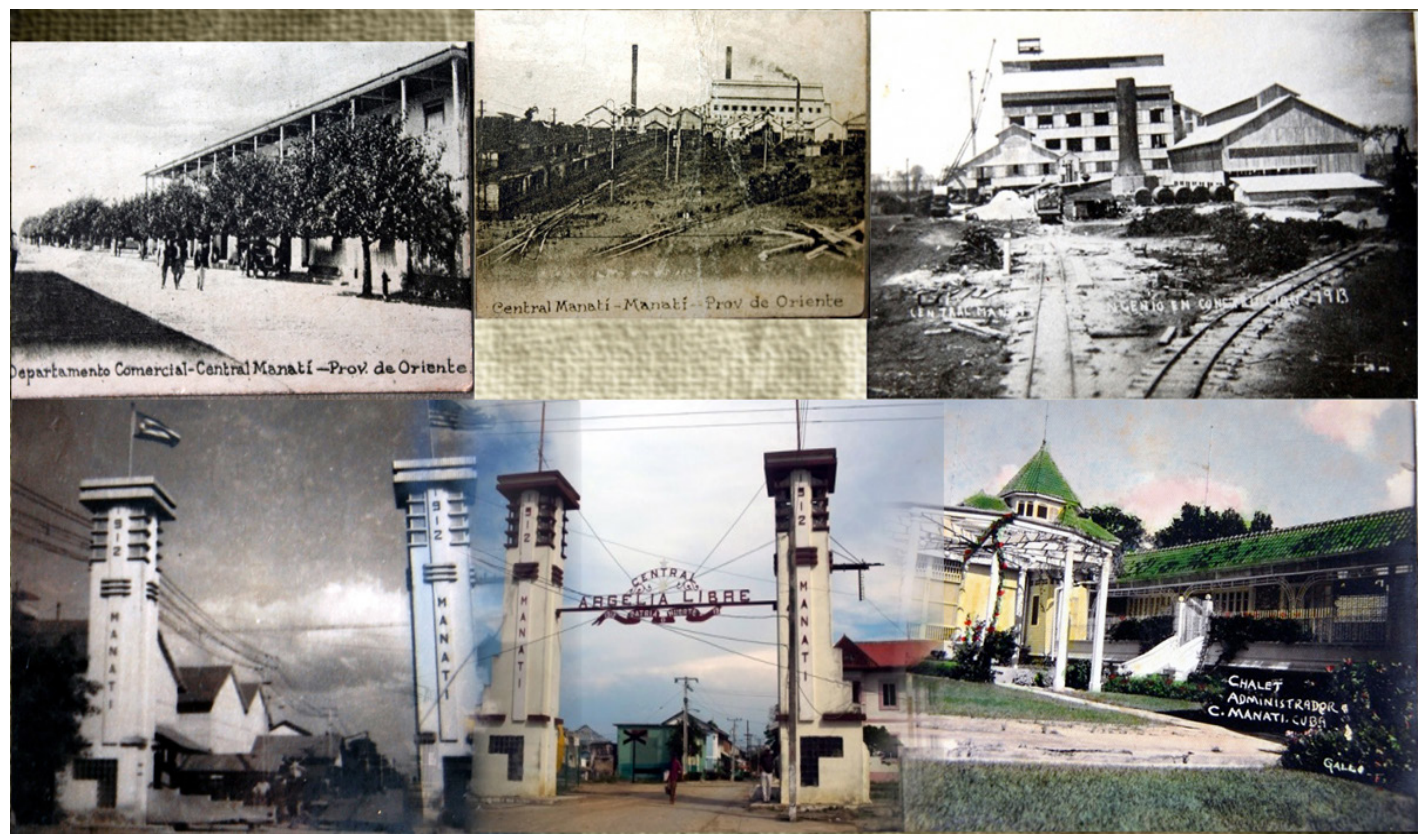


Figura 7a. Plano de las plantaciones de los centrales de Manuel Rionda. Archives of Bragha Brother Collections. New York Public Library

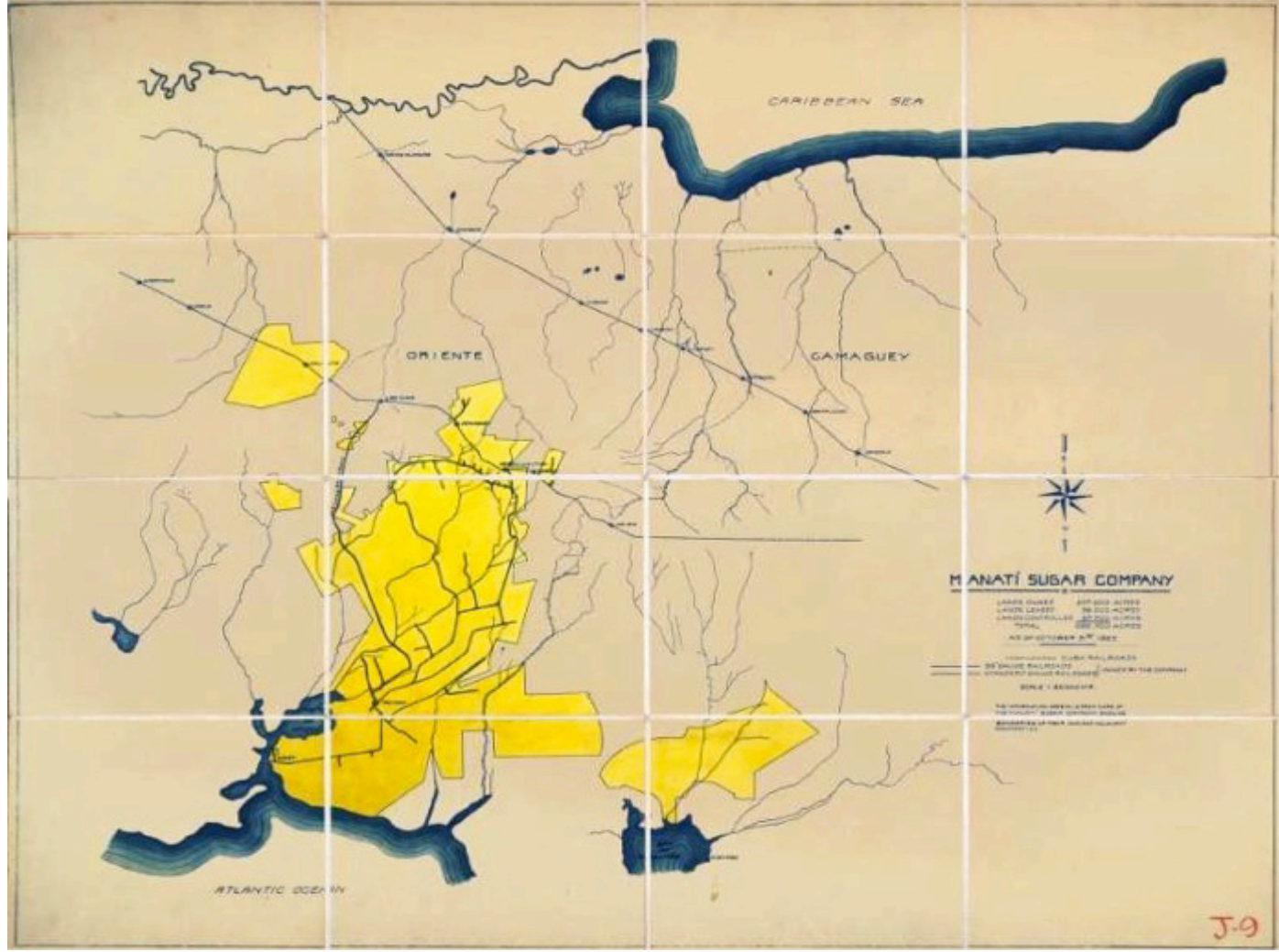

Figura 7b. Plano de las plantaciones de los centrales de Manuel Rionda. Archives of Bragha Brother Collections. New York Public Library

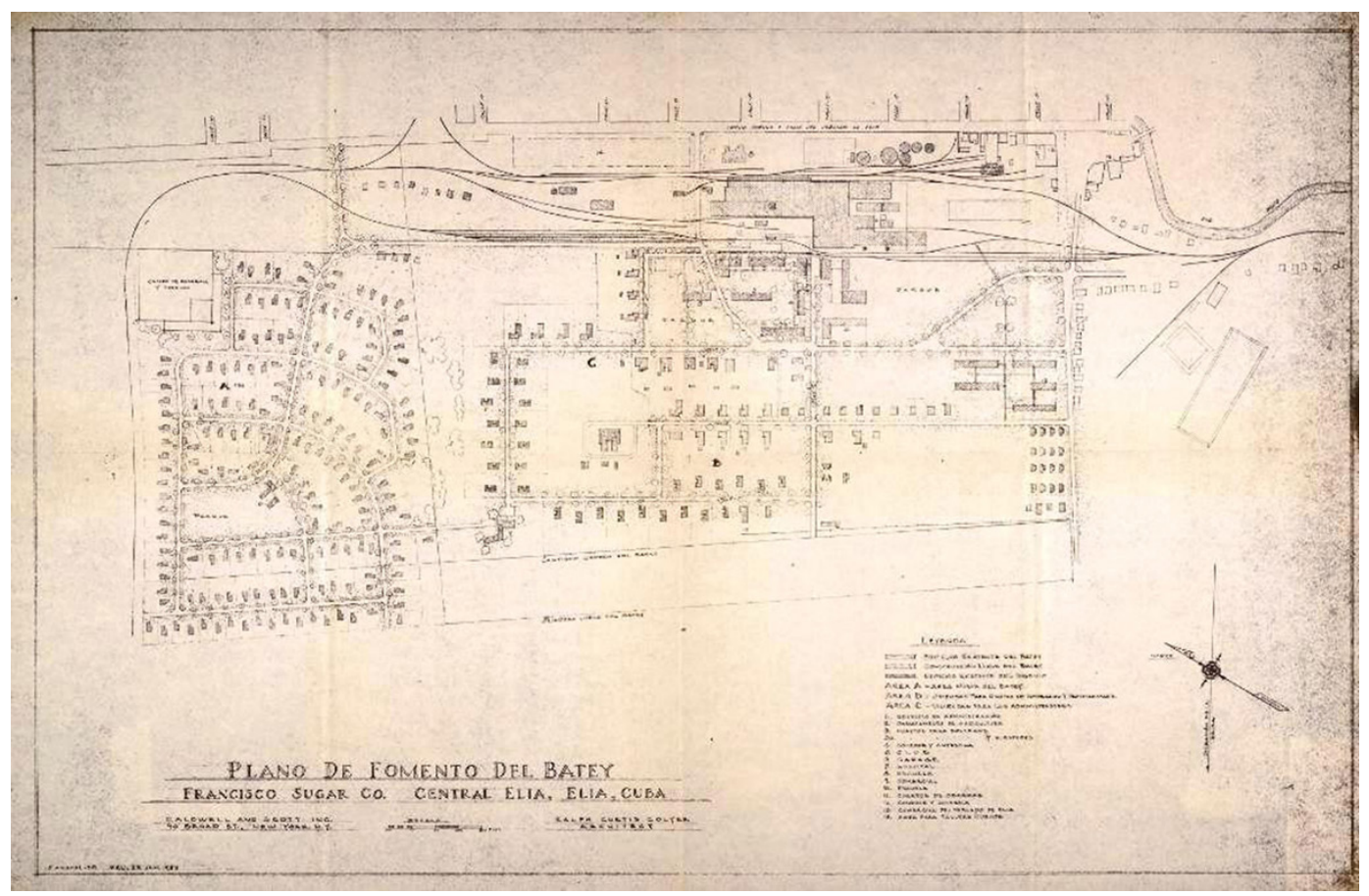


En este sentido, él atendió a la cuestión de la distancia que debía mediar entre los surcos y entre las semillas a la hora de efectuar las siembras, lo que era de particular importancia entre los hacendados cubanos de los siglos XIX y XX, ya que la caña tendía con cierta frecuencia a no crecer ni ahijar lo suficiente como para que el campo cerrase pronto. La práctica local en el occidente fue sembrar la caña de azúcar a una distancia conveniente para que al crecer las plantas casi se tocaran sus puntas. Con ello, los cultivadores garantizaban mantener la humedad del terreno y controlar el crecimiento de las malas hierbas. El reformador agrícola Francisco de Zayas creó un sistema de siembras conocido por su nombre a finales del siglo XIX. Se publicó en 1904 y se convirtió en la política oficial en la isla (Zayas, 1904). Rionda siguió en algunas de sus plantaciones el "sistema Zayas" porque había dado resultados en los campos viejos, pero en los terrenos vírgenes lo más usual fue la siembra a surco corrido, pues daba mayores rendimientos en el primer corte y las cañas maduraban más uniformemente.

Favorable a la introducción de métodos científicos aplicados al cultivo, insistía una y otra vez: "Deseo una fabrica balanceada que tenga maquinaria pero igual que cuide la pobreza de la tierra" (Archives of Bragha Brother Collections, Manuel Rionda Polledo, incoming correspondence 1896-1917, Serie 1, Box 14, Folder 15). Teniendo en cuenta el corto recorrido de la industria azucarera en la región, la estrategia dejaba al descubierto la rápida degradación de los suelos productivos. La práctica general de las plantaciones de Rionda fue sólo de cinco cultivos porque luego los campos acusaban pobreza de la caña y disminuía la sacarosa. Rionda analizó las cañas en varios distritos buscando la de más alta y más baja sacarosa con vistas a identificar de donde procedía la mejor para extender las plantaciones. Su preocupación era ¿por qué no se hace una investigación científica para aumentar la calidad de nuestras cañas y nuestras tierras? Rionda quería la opinión de varios expertos porque era consciente de que más pronto que tarde sus campos estarían exhaustos y las tierras perderían fertilidad. Su espejo era Cienfuegos, la zona más desarrollada hasta entonces; Rionda reconocía que "ellos estaban robando a la naturaleza, extendiendo plantaciones y como consecuencia los plantadores luchan por tener cañas en sus ingenios" (Archives of Bragha Brother Collections, Manuel Rionda Polledo, incoming correspondence 1896-1917, Serie 1, Box 14, Folder 15).
Rionda también se declaró ferviente partidario de la fertilización. En este sentido, siguió las experiencias con el empleo de abonos llevadas a cabo en el ingenio Portugalete (figura 8), propiedad del español Manuel Calvo, para introducirlo en sus plantaciones. En 1905, a la muerte de Calvo y siendo propietario Claudio López Bru, la publicación Cuba Agrícola, destacó los ensayos realizados en dos colonias tributarias del central con un fertilizante ideado por ellos bajo el nombre de "Fertilizante de fuerza doble para la caña de azúcar Portugalete núm. 6". Este abono también fue probado en las colonias de Rionda.

Igualmente Rionda promovió el uso de modernos implementos. En el caso del central Tuinicú el problema radicaba en la descarga de la caña dentro del conductor. Se realizaron tres intentos de aparatos descargadores pero resultaban caros. El ingenio Portugalete volvió a estar en el centro de su atención, y así, su sobrino Leandro y el propio Van Horne fueron testigos de los ensayos en dicho ingenio para observar el funcionamiento de los aparatos descargadores de caña ideados por M. V Cuervo, ingeniero civil, quien había estado de acuerdo con las sugerencias realizadas por los dos al soporte para los volteadores. Rionda también recomendó el uso de portátiles para el acarreo de la caña, ya que las carretas muchas veces causaban la prematura destrucción de los campos.

En las primeras décadas del siglo XX se repitió la experiencia con el arado de vapor, esta vez el ingeniero inglés Charles McLeod fue el encargado de ponerlo en marcha en el central Jatibonico en $17 \mathrm{ca}$ ballerías de tierra y 43 cordeles. Para McLeod este método de preparar la tierra resultaba más barato y de mayor eficacia. A ello se opuso, sin embargo, el comisionado de tierras de la compañía J. M Galdós, porque en la práctica demostró que no sólo era caro sino que el arado dejaba de trabajar durante gran parte del tiempo a causa de la lluvia y de otros obstáculos. Galdós aconsejaba mejor comprar la caña, o el uso de mulas en vez de bueyes que eran más lentos; práctica generalizada entre los productores y colonos (Archives of University of Maryland, Cash Requirements 24 May 1911-31 Jan 1912, C-29 (2)). Los reportes de McLeod fueron, asimismo, objeto de sospecha por parte de Messer, Fowler y Compañía, cuya presencia en el Caribe databa de mediados del siglo XIX. Esto reflejaba que no siempre hubo desplazamiento de las viejas por las nuevas empresas y conexiones transnacionales, sino que, en ocasiones, se erigirían como "autoridades" en la validación de los experimentos. 
Figura 8. Central Portugalete. Archivo Provincial de Las Tunas

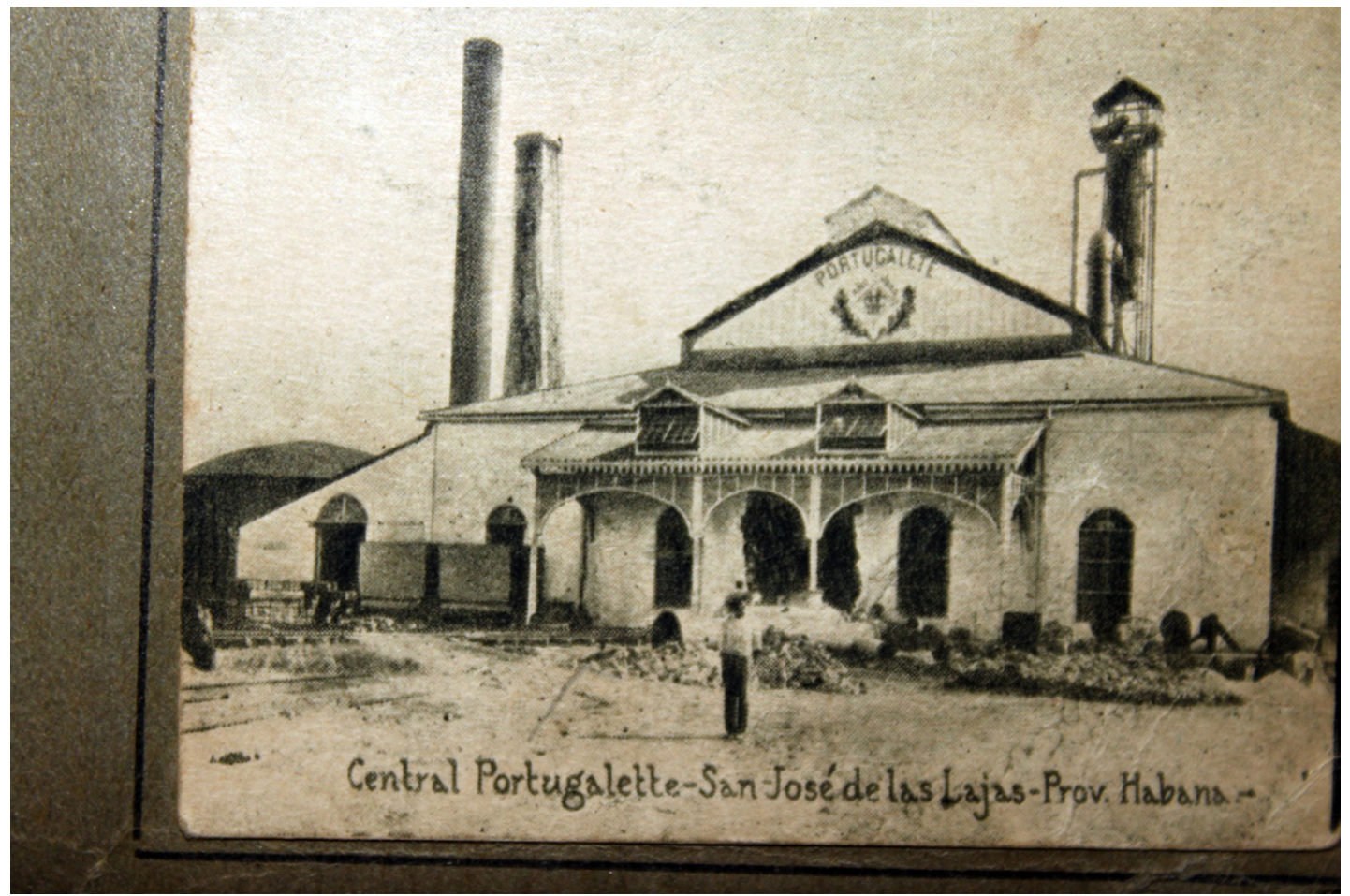

La compañía además introdujo los carros portátiles para el transporte de la caña desde la plantación a la romana. No obstante, al final optó por la tradicional carreta tirada por bueyes, porque las ruedas de los carros terminaban por depauperar más el terreno. En 1915, Rionda indicaba a Leandro que se interesara en las pruebas de fertilización realizadas por McLeod porque pensaba que estaba en el camino correcto y era una excelente manera de diversificar sus negocios.

Hay otro aspecto de interés en la agencia de los empresarios y de las sugar companys para la modernización de la plantación. Ellos se convirtieron en espacio de resistencia entre la permanencia de la variedad de caña de azúcar Cristalina y la propagación de los híbridos cañeros en los años 1920. Los historiadores documentan que los cubanos culparon a la labor del empresario azucarero norteamericano Edward Atkins de la introducción y difusión del virus del mosaico de la caña de azúcar que amenazó seriamente la industria azucarera tropical a mediados del siglo XX (Agete, 1940; McCook, 2002 a). La correspondencia y otra documentación ponen de relieve la constante experimentación de los productores en la búsqueda de variedades e híbridos cañeros más productivos y resistentes a las plagas y enfermedades. Los empre- sarios y las compañías azucareras transnacionales ensayaron con diversos híbridos hasta comprobar que el más adaptado a los suelos cubanos era el POJ2878, logrado en la Estación Experimental de Java. Un estudio más detallado demuestra que su adopción respondió, sin embargo, a la cuestión de evitar riesgos más que a la supuesta debilidad de la caña Cristalina.

\section{NUEVAS PRÁCTICAS Y SABERES CIENTIFICOS IRRUMPEN EN CUBA}

La investigación científica agrícola y la figura del experto cobró relevancia dentro del modelo agroindustrial de finales del siglo XIX. Estos dos elementos se consolidaron con la entrada de los saberes y las prácticas empresariales utilizadas por las sugar companys en sus plantaciones. Rionda y Van Horne eran empresarios y no agrónomos, su labor consistió en apoyar la ciencia e introdujeron por vez primera en el mundo azucarero cubano los laboratorios y estaciones experimentales en los centrales. En este apartado se analiza la formación del experto, en este contexto la creación de laboratorios y jardines de aclimatación, así como la utilización de los ferrocarriles para apoyar la circulación interterritorial de los científicos, agrónomos y otros expertos en sus respectivos estudios de campo. 
La importancia del personal formado en los conocimientos agronómicos y en la experimentación práctica para dirigir el cultivo se puso de relieve en Cuba a finales del siglo XIX. Los hacendados hispano-cubanos y los reformadores agrícolas defendieron que fuesen estos especialistas los encargados de dirigir las transformaciones en la agricultura cañera. Muchos propietarios recurrieron a los ingenieros agrónomos graduados en la Escuela de Agricultura del Círculo de Hacendados; así, por ejemplo, el central Caracas contrató los servicios del agrónomo Juan Bautista Jiménez. La participación de este especialista se generalizó, no obstante, en la primera mitad del siglo XX y estuvo no exenta de tensiones imperiales, científicas y empresariales.

Para Rionda la figura del experto fue fundamental para la reestructuración de la industria azucarera. Rionda reprodujo, inicialmente, el clásico sistema de redes familiares y clientelares forjadas en la colonia para encontrar el experto; en esto se muestra muy enfático:

Lo único que yo deseo es que mis sobrinos continúen dando satisfacción a nuestros amigos y aguantando o aumentando el pabellón que se ha levantado aquí de una casa española y por españoles entre americanos.

(Archives of Bragha Brother Collections, Manuel Rionda Polledo, incoming correspondence 1896-1917, Serie 1, Box 14, Folder 15).

Rionda describía un hombre local que supiera sobre el crecimiento del azúcar, que conociera los problemas laborales y el lenguaje de Cuba. Se le propuso, sin embargo, al citado Gabriel Menocal, un administrador de ingenios en Nicaragua a las órdenes de la casa Pesant y Krajewski. En este sentido, Robert Lauriandt menciona que la elección de Menocal fue política porque dependía de la aprobación de Alfred Pesant (Lauriault, 1994). Además de política, era eminentemente una respuesta comprometida con las redes establecidas en el mundo azucarero de finales del siglo XIX.

La labor de Menocal no satisfizo a Rionda quien, sólo un año después, colocó en su puesto a Francisco Coma, abogado catalán. Poco tiempo después, los accionistas de la compañía impusieron a un especialista norteamericano. En 1915, Rionda recomendaba a la Cuba Cane que empleara en la plantación a un joven químico con experiencia en los ingenios de Luisiana, así como en Niquero y Narcisa, pertenecientes a Fowler, y en su central Manatí. Aun así, Rionda envío a su sobrino Leandro a Estados Unidos para graduarse como ingeniero mecánico y, con posterioridad, lo colocó al frente del central Manatí.
En la búsqueda de personal local comprometido con Cuba Van Horne no tuvo problema. Para ello creó un laboratorio agrícola y de fabricación que fungiría, desde el inicio, según las normas de Estados Unidos, si bien acorde con el contexto local. Todavía sin explorar, una de las principales diferencias de las compañías azucareras modernas con respecto al central de finales de la colonia, fue la creación de laboratorios en los que se entrelazaban el campo y la investigación. Estos laboratorios fueron el lugar donde se formarían y se crearían una sólida reputación un personal experto en la agricultura azucarera tropical. Los dos centrales de Van Horne instalaron laboratorios dirigidos por especialistas tanto en la fabricación como en la plantación, encargados de supervisar las labores del ingenio.

La Cuba Company contrató los servicios del agente industrial Paul Karutz, un químico alemán, y más tarde de William Craib, quienes publicaron numerosas ponencias para establecer ingenios y otros negocios agroindustriales en el este de Cuba. Es poco conocido que una de las indicaciones de William Van Horne a Paul Karutz fue la creación de una estación experimental en terrenos del central Jobabo (Archives of University of Maryland, Cash Requirements 24 May 1911-31 Jan 1912, C-29 (2)). Karutz, inspirado por las estaciones estadounidenses, proponía sembrar árboles en el central para hacer atractiva la finca no sólo a turistas e investigadores sino también como laboratorio para estudiantes, agricultores y colonos interesados en aprender e informar acerca de la moderna agricultura tropical, con énfasis en la caña de azúcar. William Van Horne insistía, en cambio, en la realización de experiencias con cultivos que encontraran fácil salida en el mercado norteamericano como, por ejemplo, el maíz indiano, la alfalfa y el algodón. Van Horne subrayaba que quería un jardín de experimentación (garden-plot) para asegurar el ideal de Cuba como huerta de Estados Unidos. Karutz no se preocuparía por el dinero, sino por la forma en que pudiera ser practicable. Van Horne se hizo eco de las posturas defendidas por ciertos sectores del Departamento de Agricultura de Estados Unidos (USDA) interesados en desarrollar la nueva botánica económica para detectar oportunidades y riquezas agrícolas en los territorios recién adquiridos. Karutz pidió literatura al USDA porque estaban haciendo experimentos para mejorar las semillas y los métodos de los campesinos cubanos. La Estación practicó numerosos experimentos con el cultivo del maíz, algodón, cítricos y otras plantas comerciales. Algunas de las variedades de maíz obtenidas fueron enviadas a Estados Unidos y Argentina; así, por ejemplo, Karutz envió fibras de henequén a 
la fabrica Raffloar, Ersbloh Co. para pulsar el mercado europeo. También algunos agrónomos cubanos observaban con agrado una diversificación de la agricultura que rompiera el monopolio del azúcar en el país (Balmaseda, 1890).

Uno de los aspectos que más atención ha tenido de los historiadores de las field sciences es la formación del experto, ya que depende más de la improvisación para responder a las contingencias y condiciones propias del lugar, a diferencia del científico de laboratorio, considerado el canal ideal para conducir la ciencia (Kuclick y Kohler, 1996, pp. 1-14). En los laboratorios de la Cuba Company trabajó Noel Deer, considerado el historiador por excelencia de la industria azucarera tropical del siglo XX (Zanetti, García Muñiz y Venegas, 2001, pp. 57-154). Deer escribió uno de los libros más importantes sobre la historia de la industria azucarera basado en la experiencia práctica de sus diferentes estancias en los sitios productores. En un escrito de 1911, Deer se autodefinía como un aficionado formado al calor de la experiencia y de la observación en el lugar, a la vez que en el estudio de las ciencias aplicadas a la agroindustria:

My experience of the cane sugar industry has been divided between the positions of chemist, of factory manager, of supervising chemist, and of sugar technologist in a large Experiment Station, and as in addition it has been spent in three sugar producing districts of widely variant character, it may possibly have fitted me to take a broad view of the salient points of the industry, and so to select for detailed treatment it's more important aspects. Access, also, to a well-stocked library has enabled me to compile and present information not accessible to others less favorably situated. The advisability of a chemist devoting considerable space to the botany, agriculture, and pathology of the cane may be questioned. I, however, found it impossible to live on plantations without taking a keen interest in, and attempting to obtain something more than a something of, all phases of the production of cane sugar (...) In writing of matters which I can only hope to touch as a amateur, there is danger of serious error (Deer, 1911, p. iii).

En el ámbito de la industria azucarera tropical y el estudio de la construcción de las ciencias aplicadas al campo, las palabras de Deer ilustran la difusa frontera entre el laboratorio y el campo, entre la práctica y la teoría, entre el amateur y el experto y, sobre todo, ponen de relieve la importancia del trópico como espacio para la formación de un personal especializado en la ciencia agrícola tropical. Seguir a Deer también ejemplifica las conexiones globales al formarse en diferentes distritos azucareros del Caribe y del Sur de
Pacífico. Para entonces, la vía ideal para legitimar la autoridad de los expertos azucareros eran los viajes y estancias en los centros azucareros de todo el trópico.

Por otro lado, sus relaciones con los agrónomos y científicos formados en Cuba arrojan luz sobre las interacciones de las prácticas de estos expertos con el personal local, un tema igualmente pendiente dentro de la historia de la ciencia centrada en el lugar y la práctica. Francisco B. Cruz, ingeniero agrónomo graduado en la colonia en la Escuela de Agricultura del Círculo de Hacendados y, con posterioridad a la fundación de la república de Cuba en 1902, nombrado jefe del departamento de agricultura de la Estación Central Agronómica desde 1904 hasta 1940, mantuvo correspondencia con varios agrónomos azucareros extranjeros. Deer fue uno de ellos, pero no siempre Cruz encontró su apoyo, a diferencia del grupo de científicos, agrónomos y patólogos norteamericanos que dirigió la Estación en los primeros años de fundada (Fernández Prieto 2013, pp. 789-797).

Van Horne y la Cuba Company respaldaron el auge de los centrales del este, incluido el caso de la construcción del Manatí (Santamarina, 2001). A nivel interterritorial, la construcción del ferrocarril por WiIliam Van Horne documenta otro tipo de circulación para el Caribe hispano, inspirada en el modelo norteamericano. Vetter (2008, pp. 598-612 y 2011), por ejemplo, estudia en Estados Unidos el papel de los ferrocarriles en el establecimiento y apoyo de sitios del conocimiento, creando estaciones experimentales y como soporte de los viajes de los científicos. En Cuba, Van Horne no sólo creó estaciones experimentales y jardines de aclimatación sino que también apoyó las expediciones de agrónomos, botánicos y científicos de la Estación Experimental, así como los viajes de los expertos locales y extranjeros. Un proceso similar tuvo lugar con la United Fruit Company y las compañías de navegación, cuestión que excede a este texto.

\section{CONCLUSIONES}

La multiplicidad de agentes y sus interacciones dibuja una ciencia más abierta en un tema de particular importancia para el mundo colonial y poscolonial. En esta mirada el Caribe hispano es una asignatura pendiente, la industria azucarera cubana continuó imparablemente los "caminos del progreso", incluido su parte agrícola, poco atendida por la historiografía sobre Cuba.

El desarrollo de las plantaciones en el este demostró que la región azucarera del occidente transfirió 
saberes y técnicas agrícolas dentro de Cuba, porque los problemas ecológicos y económicos fueron iguales y las soluciones aplicadas en el occidente validaban el éxito. Las dos compañías fueron, asimismo, focos del saber y de innovación agrícola, muchas de sus actuaciones reflejaron tensiones entre nuevos y viejos saberes, nuevos y viejos actores, e incluso miradas imperiales y locales.

La formación de expertos azucareros puso de relieve un proceso de negociación con otros saberes considerados amateur y no un desplazamiento. En el campo cubano estos se convirtieron en imprescindibles para un saber que interactuó con los locales.

\section{NOTAS}

1 La plantación se refiere a los campos cultivados de caña de azúcar que, hasta la década de 1880, fueron trabajados por esclavos y formaban parte de la fábrica azucarera.

2 El término híbrido e, incluso, saberes híbridos, ha sido utilizado sobre todo desde la historia cultural y la antropología. Para el caso del azúcar, por ejemplo, Cesar Ayala menciona que la plantación azucarera caribeña del siglo XX fue un sistema híbrido para destacar una zona de frontera entre lo viejo y lo nuevo. Al hilo de

\section{FUENTES PRIMARIAS}

Archivo Provincial de las Tunas, Cuba. Cartas entre Francisco y Manuel Rionda.

Archives of University of Maryland, Estados Unidos. Cash Requirements 24 May1911-31Jan 1912, C-29 (2).

\section{BIBLIOGRAFÍA}

Agete, Fernando (1946), La caña de azúcar en Cuba. La Habana, Ministerio de Agricultura, Estación Experimental de la Caña de Azúcar.

Ayala, César (1999), American Sugar Kingdom The Plantation Economy of the Spanish Caribbean, 1898-1934. Berkeley, The University of North Carolina Press.

Balmaseda, Francisco Javier (1890), Tesoro del agricultor cubano. Manuales para el cultivo de las principales plantas propias del clima de Cuba, 2 (ed.). Habana, Propaganda Literaria.

Chambers, D.W. \& R. Gillespie(2001), "Locality in the History of Science. Technoscience, and Indigenous Knowledge," Osiris 15, pp. 221-240.

Curry-Machado, Jonathan (2011), Cuban Sugar Industry: Transnational Networks and Engineering Migrants in MidNineteenth Century Cuba. New York, Palgrave MacMillan.

Deer, Noel (1911), Cane sugar: A textbook on the agriculture of the sugar cane, the manufacture of cane sugar and the analysis of sugar house products. London.
Los fondos de las sugar companys son un caudal de información para la historia de la ciencia y del ambiente poco explorado. A partir de su estudio más minucioso se podrá conocer la forma en que la ciencia azucarera global se conformó con prácticas y saberes diversos, pero acordes con el manejo de los recursos locales.

\section{AGRADECIMIENTOS}

Este trabajo forma parte del proyecto de investigación HAR2012-37455-C03-01 (MINECO) y el proyecto RYC2009-04030.

este razonamiento, pienso que es un concepto fructífero y poco explorado para los historiadores de la ciencia interesados en la producción de saberes de las mercancías agrícolas tropicales.

3 Este término fue utilizado por mí para definir la contribución de cada espacio productor al conocimiento científico agrícola global. Ver, Fernández Prieto, Leida (2013), "Islands of knowledge: Science and Agriculture in the History of Latin American and the Caribbean", Isis, vol. 104, No. 4, (December), pp. 789-797.

Archives of Bragha Brother Collections. Manuel Rionda Polledo, incoming correspondence 1896-1917, Serie 1, Box 14, Folder 15. New York Public Library. Estados Unidos.

Dye, Allan (1998), Cuban sugar in the age of mass production: Technology and the economics of the sugar central, 1899-1929. Stanford, California, University Press.

Fernández Prieto, Leida (2005), Cuba Agrícola. Mito y Tradición, 1878-1920. Madrid, CSIC.

Fernández Prieto, Leida (2008), Espacios de poder ciencia y agricultura: el Círculo de Hacendados de la Isla de Cuba. SevillaMadrid, Diputación Provincial de Sevilla-, CSIC.

Fernández Prieto, Leida (2013), “Islands of knowledge: Science and Agriculture in the History of Latin American and the Caribbean", Isis, 104 (4), december, pp. 789-797.

Funes Monzote, Reinaldo (2004), De Bosque a sabana. Azúcar, deforestación y medio ambiente en Cuba: 1492-1926. México, Estado Libre y Gobierno de Quintana Roo, siglo XXI editores.

García Collazo, Enrique (2002), "Empresarios asturianos en Cuba (1840-1920)”, Revista de Indias, vol. LXII, núm. 225, pp. 535-558. 
Iglesias García, Fe (1999), Del ingenio al central. La Habana, Editorial de Ciencias Sociales.

Kuclick, Henrika y Kohler, Robert E. (1996), "Introduction”, Osiris (Science in the Field), vol. 11, pp. 1-14.

Lauriault, Robert Nairne (1994), Virgin Soil: The Modernization of Social Relations on a Cuban Sugar Estate- The Francisco Sugar Company, 1898-1921. Ph.d Dissertation, University of Florida, [en línea], disponible en: https://ia600507.us.archive.org/23/ items/virginsoilmodern00laur/virginsoilmodern00laur.pdf

McAvoy, Muriel (2003), Sugar Baron. Manuel Rionda and the fortunes of the Pre-Castro Cuba. Gainsville, University of Florida Press.

McCook, Stuart (2002a), States of Nature. Science, Agriculture and Environment in the Spanish Caribbean, 1760-1940. Austin, University of Texas Press.

McCook, Stuart (2002b), "Las epidemias liberales: Agricultura, ambiente y globalización en Ecuador (1790-1930)". En: García Martínez, B. y M. del R. Prieto (Comps.), Estudios sobre historia y ambiente en América II. Norteamérica, Sudamérica y el Pacífico, El Colegio de México, Instituto Panamericano de Geografía e Historia, pp. 223-256.

McCook, Stuart (2009), “'The World Was My Garden': Tropical Botany and Cosmopolitanism in American Science, 1898-1935". En: Mccoy A. and Scarano, F., Colonial Crucible: Empire in the Making of the Modern American State, Madison, University of Wisconsin Press, pp. 499-507.

McGillivray, Gillian (2009), Blazing Cane: Sugar Communities, Class, and State formation in Cuba, 1868-1919. Durham, Duke University Press.

Moreno Fraginals, Manuel (1978), El Ingenio. Complejo económico y social del azúcar, 3ts. La Habana, Editorial de Ciencias Sociales.

Nadel, Joshua Henry (2007), Processing Modernity: Social and Cultural Adaptation in Eastern Cuba, 1902-1933. Ph. d. Dissertation. [en línea] University of Michigan, disponible en: http://search.proquest.com/docview/304839785

Pérez de la Riva, J. (1975), El barracón y otros ensayos. La Habana, Editorial de Ciencias Sociales.

Pérez de la Riva, J. (2004), La conquista del espacio cubano. La Habana. Fundación Fernando Ortiz.

Pérez de la Riva, J. (1968), "Una isla con dos historias". En: Cuba Internacional, La Habana, pp. 22-39.

Pérez Jr., Louis A (1983), Cuba between empires, 1878-1902. Pittsburgh, University of Pittsburgh.

Pino Santos, Oscar (1960), El imperialismo norteamericano en la economía de Cuba. La Habana, Editorial Lex.

Raby, Megan (2013), Making Biology Tropical: American Science in the Caribbean, 1898-1963. Ph.D., University of WisconsinMadison (forthcoming).

Reynoso, Álvaro (1862), Ensayo sobre el cultivo de la caña de azúcar. Habana, Imprenta del Tiempo.
Sagra, Ramón de la (1863), Cuba en 1860. O sea cuadro de sus adelantos en la población, la agricultura, el comercio y las rentas públicas. París, Librería de L. Hachette.

Santamaría García, Antonio (2001), Sin azúcar no hay país. La industria azucarera y la economía cubana (1919-1939). CSIC, EEHA, Universidad y Diputación de Sevilla.

Santamarina, Juan Carlos (1995), The Cuba Company and Cuban Development, 1900-1959. Rutgers, The State University of New Jersey.

Santamarina, Juan Carlos (2001), "The Cuba Company and eastern Cuba's economic development, 1900-1959", Essays in Economic and Business History, pp. 75-90.

Soluri, John (2005), Banana cultures: Agriculture, Consumption, and Environmental Change in Honduras and the United States. Austin, The University of Texas Press.

Steven C. Topick y Allen Wells (1997), The second conquest of Latin America. Coffe, Henequen, and Oil during the Export Boom 1850-1930. Austin, The University of Texas Press.

Tomich, Dave y Reinaldo Funes Monzote (2001), "Naturaleza, tecnología y esclavitud en Cuba. Frontera azucarera y revolución industrial, 1815-1870". En: Piqueras Arenas, José A. (ed), Trabajo libre y coactivo en sociedades de plantación, Madrid, Siglo XXI, pp. 75-120.

Tucker, R. P. (2000), Insatiable Appetite. The United States and the Ecological Degradation of the Tropical World, Berkeley, University of Carolina Press.

Venegas Delgado, Hernán (2001), La región en Cuba. Un ensayo de interpretación historiográfica. Santiago de Cuba, Editorial Oriente.

Vetter, Jeremy (2005), The regional development of science: Knowledge, environment, and field work in the U.S. Central Plains and Rocky Mountains, 1860-1920. Dissertations available from ProQuest. Paper AAI3179825, [en línea], disponible en: http://repository.upenn.edu/dissertations/AAI3179825

Vetter, Jeremy (ed.) (2011), Knowing Global Environments: New Historical Perspectives in the Field Sciences. New Brunswick, Rutgers University Press.

Vetter, Jeremy (2008), "Field Science in the Railroad Era: the tools of Knowledge Empire in the America West, 1869-1916", História, Ciências, Saúde, Manghinos, Rio de Janeiro, 15 (3), pp. 597-613.

Zanetti Lecuona, Oscar y Alejandro García (1976), United Fruit Co.: un caso de dominio imperialista en Cuba. La Habana, Editorial de Ciencias Sociales.

Zanetti Lecuona, Oscar, Hernán Venegas Delgado, y Humberto García Muñiz (2001), “Nöel Deerr en la Guayana Británica, Cuba y Puerto Rico, 1897-1921", Revista Mexicana del Caribe, 6 (11), pp. 57-154.

Zayas y Jiménez, Francisco de (1904), Política agrícola de la República. Nuevo método de siembras y cultivo de la caña de azúcar. La Habana, Liga Agraria de Cuba. 